\title{
As Unidades de Pronto-Atendimento na Política Nacional de Atenção às Urgências
}

\section{| ${ }^{1}$ Mariana Teixeira Konder, ${ }^{2}$ Gisele O'Dwyer |}

Resumo: A Política Nacional de Atenção às Urgências foi fruto de grande insatisfação com o atendimento nas emergências hospitalares. As UPAs constituíram o principal componente de atendimento pré-hospitalar fixo da política. O objetivo do estudo foi analisar as portarias ministeriais que regulamentaram a criação das UPAs, procurando compreender seu padrão de implantação. Foram analisadas as portarias que regulamentaram as UPAs entre 2008 e 2013, à luz da Teoria da Estruturação, de Giddens. No conjunto, essas portarias expressam a pretensão de que as UPAs fossem instaladas de forma estratégica para a configuração de redes de atenção às urgências, propondo diferenciação em relação aos pronto-socorros produtores de "consultas de emergência". No entanto, o padrão de implantação das UPAs foi de expansão acelerada, sem efetiva organização em rede, projetando suspeita de uma reprodução do modelo tradicional de pronto-socorros. A esfera federal destacouse pela intensa produção normativa, assumindo forte papel indutor. A significativa adesão das unidades da federação explica a ampla legitimação, enquanto modalidade da estruturação, alcançada por essa política. Assim, a convergência de interesses em torno da UPA permitiu rápida expansão e enorme aporte de recursos para essa política, apesar de essa estratégia pouco agregar para o enfrentamento dos problemas da atenção às urgências.

> Palavras-chave: atendimento de emergência pré-hospitalar; serviços médicos de emergência; Sistema Único de Saúde.

\footnotetext{
1 Departamento de

Administração e Planejamento em Saúde, Escola Nacional de Saúde Pública, Fundação Oswaldo Cruz. Rio de JaneiroRJ, Brasil. Endereço eletrônico marianakonder@gmail.com

2 Departamento de Administração e Planejamento em Saúde, Escola Nacional de Saúde Pública, Fundação Oswaldo Cruz. Rio de JaneiroRJ, Brasil. Endereço eletrônico: odwyer@ensp.fiocruz.br
} 
$\mathrm{O}$ atendimento às urgências e emergências tem sido investigado em vários países, em função do seu impacto na atenção à saúde e nos indicadores de morbi-mortalidade. No Brasil, diversos autores vêm discutindo a atenção prestada às urgências e emergências sob enfoques variados. Destacamos aqui a gestão da superlotação das emergências hospitalares (SANTOS et al., 2003; BITTENCOURT; HORTALE, 2009; O'DWYER et al., 2009), problema largamente anunciado pela academia, assim como pela imprensa.

A Política Nacional de Urgência (PNAU), formulada no Brasil em 2003, foi fruto de uma grande insatisfação com o atendimento nas emergências hospitalares, que culminou com a mobilização de diversos atores, como: o Conselho Nacional de Secretários de Saúde (CONASS), a Rede Brasileira de Cooperação em Emergência (RBCE), além do próprio Governo Federal (O'DWYER, 2010). Nesse processo, destaca-se a criação de um novo ente gestor no organograma do Ministério da Saúde, a Coordenação Geral de Urgência e Emergência - CGUE(BRASIL, 2003c), primordial para a formulação e implantação dessa política.

A construção da política federal para atenção às urgências no Brasil envolveu três momentos principais: de 1998 até 2003, há predomínio da regulamentação; entre 2004 e 2008, há grande expansão do Serviço de Atendimento Móvel de Urgência (SAMU); e a partir de 2009, predomina a implantação do componente fixo da atenção pré-hospitalar, as Unidades de Pronto-atendimento - UPAs (MACHADO et al., 2011).

A PNAU teve como marcos o financiamento federal, a regionalização e a capacitação dos profissionais. Apresentou-se como uma normatização coerente para oferecer cuidado integral na atenção às urgências (O'DWYER, 2010). Tem entre seus méritos a superação da concepção de urgência apenas baseada em critérios clínicos, propondo o conceito ampliado de urgência, que incorpora a concepção advinda do usuário. A partir da PNAU, a diferenciação entre urgência/emergência é superada e substituída pelo termo "urgência" em níveis crescentes de gravidade (BRASIL, 2003a). O componente pré-hospitalar 
móvel ou SAMU (BRASIL, 2003b) foi o primeiro componente da política a ser implementado no Brasil.

O SAMU é um serviço de socorro pré-hospitalar móvel, no qual o usuário, através do acesso telefônico gratuito pelo número 192, solicita atendimento em casos de urgências. Tem um componente regulador, a Central Médica de Regulação, e um componente assistencial, as equipes das ambulâncias. Um dos seus pressupostos é ser observatório da rede de atenção às urgências e estar sob a gestão de comitês de urgência nos níveis nacional, estadual, regional e municipal (O'DWYER, 2010).

Esse novo serviço pretende organizar o acesso aos serviços de emergência hospitalar, aos leitos hospitalares e regular o acesso à rede de forma mais ampla. Portanto, o SAMU consiste em uma nova porta de entrada no sistema, que acontece a partir das chamadas telefônicas e atendimento por ambulância, conforme critérios de gravidade. Atualmente, o SAMU está presente em todos os estados brasileiros, cobrindo quase 3.000 municípios. Isto corresponde a uma cobertura de 70\% da população brasileira (SAGE, 2013).

As UPAs se contituíram no principal componente fixo de urgência préhospitalar e têm se estabelecido como importante ponto de acesso ao sistema, instituindo-se enquanto unidades intermediárias entre a atenção básica e as emergências hospitalares. São classificadas em três diferentes portes (BRASIL, 2008, 2009, 2011b, 2011 c), de acordo com a população do município-sede, a área física, número de leitos disponíveis, gestão de pessoas e a capacidade diária de realizar atendimentos médicos.

No que diz respeito ao desenvolvimento da política de urgências, o Ministério da Saúde e a CGUE propõem que a Rede de Atenção às Urgências (RAU) tem a finalidade de articular e integrar todos os equipamentos de saúde, objetivando ampliar e qualificar o acesso humanizado e integral aos usuários em situação de urgência/emergência nos serviços de saúde, de forma ágil e oportuna (BRASIL, 2011a). ARAU está entre as redes de atenção prioritárias do Ministério da Saúde e foi constituída considerando que o atendimento aos usuários com quadros agudos deve ser prestado por todas as portas de entrada dos serviços de saúde do SUS. Essa rede considera os componentes pré-hospitalares - atenção básica, SAMU e 
UPA -, o componente hospitalar e a atenção domiciliar, tendo como interfaces promoção e prevenção, acolhimento, qualificação profissional, informação e regulação (BRASIL, 2011a).

$\mathrm{Na}$ nova proposta de rede permanece o projeto de expansão dos serviços de atendimento às urgências, já evidenciado no começo dos anos 2000, assim como o forte financiamento federal. Entre as propostas de investimentos previstos até 2018, destacamos algumas: para o componente pré-hospitalar, 100\% de cobertura e regionalização pelo SAMU; ampliação para 1.096 UPAs; criação de 900 Salas de Estabilização; ${ }^{1}$ e investimento e qualificação para as portas hospitalares de urgência, considerando hospitais com 100 ou mais leitos.

Devido ao desenvolvimento recente no cenário nacional, ainda é pequena a produção bibliográfica sobre o atendimento pré-hospitalar. Entretanto, as experiências no Brasil têm gerado alguns estudos que contextualizam o atendimento às urgências pré-hospitalares móveis no país (MINAYO; DESLANDES, 2008; TANNEBAUM; ARNOLD, 2001; EVANGELISTA et al., 2008; CICONET et al., 2008, LIMA; RIVERA, 2010; O'DWYER, 2010; O’DWYER; MATTOS, 2012; O’DWYER; MATTOS, 2013; O'DWYER et al.; 2013).

Como discutido até o momento, a atual política de urgência privilegia uma rede integrada de urgência e propõe sua franca expansão. Infelizmente, essa política foi implementada de forma fragmentada, começando pelo SAMU e posteriormente regulando a UPA, propondo modificar o padrão de atendimento nos antigos prontos-socorros. Por esses argumentos, objetiva-se analisar, neste artigo, as portarias ministeriais que regulamentam a implantação das UPAs e seu padrão de implantação ocorrido no Brasil até 2013.

\section{Metodologia}

Foram analisadas as portarias ministeriais que regulamentam as Unidades de Pronto-atendimento, instituídas entre 2008 e 2013, incluindo a primeira regulamentação e a mais recente (quadro 1). As portarias foram analisadas a partir das seguintes categorias: argumentos, atribuiçôes, gestão, e financiamento. 
Pronto-atendimento e da Rede de Atenção às Urgências, Brasil, 2012.

\begin{tabular}{|c|c|c|c|}
\hline $\begin{array}{l}\text { Normativa/ } \\
\text { ano de } \\
\text { publicação }\end{array}$ & Situação & Objetivo & $\begin{array}{l}\text { Ministro } \\
\text { da Saúde }\end{array}$ \\
\hline $\begin{array}{l}\text { Portaria } \mathrm{n}^{\circ} \\
1.863 / 2003\end{array}$ & Revogada & $\begin{array}{l}\text { Institui a Política Nacional de Atenção } \\
\text { às Urgências, a ser implantada em todas } \\
\text { as unidades federadas, respeitadas as } \\
\text { competências das três esferas de gestão. }\end{array}$ & $\begin{array}{l}\text { Humberto } \\
\text { Costa }\end{array}$ \\
\hline $\begin{array}{l}\text { Portaria } n^{o} \\
2.072 / 2003\end{array}$ & Em vigor & $\begin{array}{l}\text { Institui o Comitê Gestor Nacional de } \\
\text { Atenção às Urgências. }\end{array}$ & $\begin{array}{l}\text { Humberto } \\
\text { Costa }\end{array}$ \\
\hline $\begin{array}{l}\text { Portaria } n^{\circ} \\
2.922 / 2008\end{array}$ & Revogada & $\begin{array}{l}\text { Estabelece diretrizes para o fortalecimento } \\
\text { e implementação do componente } \\
\text { Organização de redes loco-regionais de } \\
\text { atenção às urgências da Política Nacional de } \\
\text { Atenção às Urgências. }\end{array}$ & $\begin{array}{l}\text { José } \\
\text { Gomes } \\
\text { Temporão }\end{array}$ \\
\hline $\begin{array}{l}\text { Portaria } \mathrm{n}^{\circ} \\
1.020 / 2009\end{array}$ & Revogada & $\begin{array}{l}\text { Estabelece diretrizes para a implantação } \\
\text { do componente pré-hospitalar fixo para } \\
\text { a organização de redes locorregionais } \\
\text { de atenção integral às urgências em } \\
\text { conformidade com a Política Nacional de } \\
\text { Atenção às Urgências. }\end{array}$ & $\begin{array}{l}\text { José } \\
\text { Gomes } \\
\text { Temporão }\end{array}$ \\
\hline $\begin{array}{l}\text { Portaria } n^{\circ} \\
1600 / 2011\end{array}$ & Revogada & $\begin{array}{l}\text { Reformula a Política Nacional de Atenção } \\
\text { ás Urgências e institui a Rede de Atenção às } \\
\text { Urgências no Sistema Único de Saúde (SUS). }\end{array}$ & $\begin{array}{l}\text { Alexandre } \\
\text { Padilha }\end{array}$ \\
\hline $\begin{array}{l}\text { Portaria } n^{\circ} \\
1.601 / 2011\end{array}$ & Revogada & $\begin{array}{l}\text { Estabelece diretrizes para a implantação } \\
\text { do componente Unidades de Pronto- } \\
\text { atendimento (UPA } 24 \mathrm{~h} \text { ) e o conjunto de } \\
\text { serviços de urgência } 24 \text { horas da Rede de } \\
\text { Atenção às Urgências, em conformidade com } \\
\text { a Política Nacional de Atenção às Urgências. }\end{array}$ & $\begin{array}{l}\text { Alexandre } \\
\text { Padilha }\end{array}$ \\
\hline
\end{tabular}




\begin{tabular}{|c|c|c|c|}
\hline $\begin{array}{c}\text { Normativa/ } \\
\text { ano de } \\
\text { publicação }\end{array}$ & Situação & Objetivo & $\begin{array}{l}\text { Ministro } \\
\text { da Saúde }\end{array}$ \\
\hline $\begin{array}{l}\text { Portaria } \mathrm{n}^{\mathrm{o}} \\
2.648 / 2011\end{array}$ & Em vigor & $\begin{array}{l}\text { Redefine as diretrizes para a implantação } \\
\text { do componente Unidades de Pronto- } \\
\text { atendimento (UPA 24h) e o conjunto de } \\
\text { serviços de urgência } 24 \text { horas da Rede de } \\
\text { Atenção às Urgências, em conformidade com } \\
\text { a Política Nacional de Atenção às Urgências. }\end{array}$ & $\begin{array}{l}\text { Alexandre } \\
\text { Padilha }\end{array}$ \\
\hline $\begin{array}{l}\text { Portaria } \mathrm{n}^{\mathrm{o}} \\
2.820 / 2011\end{array}$ & Revogada & $\begin{array}{l}\text { Dispõe sobre o incentivo financeiro de } \\
\text { investimento para o componente Unidades } \\
\text { de Pronto-atendimento (UPA 24h) e o } \\
\text { conjunto de serviços de urgência } 24 \text { horas } \\
\text { da Rede de Atenção às Urgências, em } \\
\text { conformidade com a Política Nacional de } \\
\text { Atenção às Urgências. }\end{array}$ & $\begin{array}{l}\text { Alexandre } \\
\text { Padilha }\end{array}$ \\
\hline $\begin{array}{l}\text { Portaria } n^{\circ} \\
2.821 / 2011\end{array}$ & Revogada & $\begin{array}{l}\text { Dispõe sobre o incentivo financeiro de } \\
\text { custeio para o componente Unidades de } \\
\text { Pronto-atendimento (UPA } 24 \mathrm{~h} \text { ) e o conjunto } \\
\text { de serviços de urgência } 24 \text { horas da Rede de } \\
\text { Atenção às Urgências, em conformidade com } \\
\text { a Política Nacional de Atenção às Urgências. }\end{array}$ & $\begin{array}{l}\text { Alexandre } \\
\text { Padilha }\end{array}$ \\
\hline $\begin{array}{l}\text { Portaria } n^{\circ} \\
1.171 / 2012\end{array}$ & Em vigor & $\begin{array}{l}\text { Dispõe sobre o incentivo financeiro de } \\
\text { investimento para a construção e ampliação } \\
\text { no âmbito do componente Unidades de } \\
\text { Pronto-atendimento (UPA } 24 \mathrm{~h} \text { ) e do } \\
\text { conjunto de serviços de urgência } 24 \text { horas } \\
\text { da Rede de Atenção às Urgências, em } \\
\text { conformidade com a Política Nacional de } \\
\text { Atenção às Urgências. }\end{array}$ & $\begin{array}{l}\text { Alexandre } \\
\text { Padilha }\end{array}$ \\
\hline $\begin{array}{l}\text { Portaria no } \\
1.172 / 2012\end{array}$ & Em vigor & $\begin{array}{l}\text { Dispõe sobre o incentivo financeiro de } \\
\text { custeio para o componente Unidades de } \\
\text { Pronto-atendimento (UPA } 24 \mathrm{~h} \text { ) e o conjunto } \\
\text { de serviços de urgência } 24 \text { horas da Rede de } \\
\text { Atenção às Urgências, em conformidade com } \\
\text { a Política Nacional de Atenção às Urgências. }\end{array}$ & $\begin{array}{l}\text { Alexandre } \\
\text { Padilha }\end{array}$ \\
\hline
\end{tabular}

Fonte: elaboração própria. 
Para esta análise, consideramos a Teoria da Estruturação, de Giddens (1984).

Segundo o autor, a estrutura é formada por regras e recursos. $\mathrm{O}$ aspecto normativo das regras refere-se às práticas do ponto de vista dos direitos e obrigações e dos modos pelos quais as práticas podem ser executadas. Os recursos são as facilidades ou base de poder a que o agente tem acesso e que ele manipula para influenciar a interação com o outro. Portanto, consideraram-se as portarias como regras e recursos estruturais para a implementação da política (GIDDENS, 1984).

São três as modalidades da estruturação que servem para esclarecer as principais dimensões da dualidade da estrutura: significação, que a partir de um esquema interpretativo é possibilitada pela comunicação; dominação, que depende da mobilização de recursos alocativos e autoritários; e legitimação, exercida a partir da sanção de normas. Segundo a metodologia proposta, discutiremos no artigo a modalidade de legitimação (GIDDENS, 1984).

\section{Resultados}

\section{Os argumentos contidos nas portarias}

A estratégia das UPAs é justificada com recurso a argumentos de natureza variada. Todas as portarias consideram a alta relevância epidemiológica e social dos quadros de urgência correlatos ao perfil de morbimortalidade do Brasil (BRASIL, 2008, 2009a, 2011b, 2011c). Diversas portarias e políticas são enumeradas, ora referindo-se à necessidade de sua implementação e/ou cumprimento, ora referindo-se ao marco legal/técnico por elas estabelecido, para fundamentar a implantação das UPAs. A Portaria no 2.048/2002, a PNAU e sua reedição em 2011, a Política Nacional de Humanização e a Política Nacional de Atenção Básica são mencionados em todas as portarias referentes às UPAs. O QualiSUS-urgência somente é mencionado na primeira portaria (2.922/2008) e o Pacto pela Saúde deixa de ser citado na última portaria(2.846/2011).

A expansão da rede nacional do SAMU-192 e sua necessidade de retaguarda são justificativas para implantação e expansão das UPAs em todas as versões das portarias. A implantação das UPAs é correlacionada ao processo de reconfiguração da rede assistencial no âmbito do SUS em todos os documentos. Na primeira portaria, enuncia-se a prioridade de o Ministério da Saúde implementar um vigoroso programa de investimentos para alterar a configuração de Redes de Atenção à Saúde e prover atendimento de urgência qualificado e oportuno dentro 
dessas redes (BRASIL, 2008).Nas portarias subsequentes (BRASIL, 2011b, 2011c),essa referência à rede se encontra na menção à Portaria no 479/2010 do Ministério da Saúde, que estabelece diretrizes para organização de Redes de Atenção à Saúde no âmbito do SUS.

Em todas as portarias, destaca-se a necessidade de estabelecer condiçōes de financiamento para organização da rede de atenção às urgências. Nas portarias editadas em 2011, aparece pela primeira vez a questão dos sistemas de informação, em que a alimentação dos Bancos de Dados Nacionais dos Sistemas de Informação do SUS, ambulatorial e hospitalar, torna-se requisito obrigatório, implicando suspensão de repasses financeiros em caso de não alimentação.

\section{Atribuiçóes específicas segundo os documentos}

Desde a primeira portaria (2.922/2008), a definição para as UPAs tem formulação constante, estabelecendo que as mesmas são "[...] o estabelecimento de saúde de complexidade intermediária entre as Unidades Básicas de Saúde, Unidades de Saúde da Família e a Rede Hospitalar devendo com estas compor uma rede organizada de atenção às urgências". Assim, como visto, na fundamentação da implantação desse componente, o conceito de rede e a busca por sua configuração estão sempre presentes (BRASIL, 2008, 2009a, 2011b, 2011c).

As competências atribuídas às UPAs dentro da rede de atenção às urgências (quadro 2) destacam seu caráter assistencial, mas sobretudo sua natureza de pronto-atender, ao definir que o acolhimento às demandas dos usuários deve ocorrer sempre. A realização de consultas médicas, inclusive aos casos de menor gravidade, estabelece uma lógica de trabalho mais permeável às demandas consideradas não urgentes. Desse modo, a legislação recusa a possibilidade de a unidade operar apenas pela lógica de urgência própria aos profissionais de saúde (GIGLIO-JACQUEMOT, 2005). A perspectiva de rede também se expressa na obrigatoriedade dessas unidades terem de se articular com outros componentes da rede, sendo retaguarda para SAMU e atenção básica e recorrendo aos hospitais e centrais de regulação, através da pactuação de grades de referência e contrarreferência. A consubstanciação de um fluxo entre os níveis de atenção é fundamental, pois não cabe a essas unidades, considerando tanto seus objetivos, quanto sua estrutura física, permanecer com pacientes por mais de 24 horas (BRASIL, 2008, 2009a, 2011b, 2011c). 
- Acolher sempre as demandas por atendimento.

- Articular-se com a rede em fluxos de referência e contrarreferência por meio das CRM.

- Prestar atendimento qualificado e resolutivo a quadros clínicos agudos ou crônicos agudizados.

- Prestar primeiro atendimento aos quadros cirúrgicos e de trauma.

- Fornecer retaguarda às urgências atendidas na $\mathrm{AB}$.

- Funcionar como local de estabilização de pacientes atendidos pelo SAMU.

- Realizar consulta médica em regime de pronto-atendimento aos casos de menor gravidade.

- Realizar procedimentos médicos e de enfermagem adequados aos casos demandados à unidade

- Prestar apoio diagnóstico e terapêutico $24 \mathrm{~h}$ por dia, 7 dias por semana.

- Manter em observação clínica por até 24 h para elucidação diagnóstica ou estabilização clínica.

- Encaminhar para internação em hospitais, por meio das CRM, pacientes com quadros não resolvidos após $24 \mathrm{~h}$.

- Referenciar e contrarreferenciar adequadamente para rede.

- Solicitar retaguarda técnica ao SAMU sempre que necessário.

Fonte: Brasil (2008, 2009, 2011b, 2011c).

Legenda: AB - Atenção Básica; CRM - Centrais de Regulação Médica.

Divididas em diferentes portes de estrutura física, as UPAs têm o número mínimo de médicos atuando nas unidades correlacionado com seu porte. Inicialmente, havia a exigência de igual proporção de médicos clínicos e pediatras (BRASIL, 2008). Subsequentemente, porém, esse critério começa a ser flexibilizado, sendo a referência numérica por porte de UPA feita a médicos, sem indicar a especialidade (BRASIL, 2009, 2011b, 2011c). Essa foi uma estratégia compensatória para a dificuldade de lotar pediatras e clínicos nas UPAs. O processo de flexibilização também abriu espaço para a especialização, como no caso da legislação em vigor, que prevê a possibilidade de, em situações excepcionais, determinada UPA apresentar outro perfil de especialidades médicas, considerando necessidade local e acordo com a CGUE (BRASIL, 2011c). 
A forma de gestão das urgências foi contemplada na política desde os primeiros documentos. Entretanto, as modificações de regulação propostas ao longo do tempo - PNAU em 2003 e RAU em 2011 - não superaram a inoperância da regulação. A gestão foi estruturada a partir de múltiplos níveis, estando previsto um Comitê Gestor Nacional de Urgência, idealizado como um espaço formal de discussão, avaliação e implementação de correções necessárias à permanente adequação do sistema de atenção integral às urgências (BRASIL, 2003c).Também foram previstos comitês estaduais, regionais e municipais.

Segundo a RAU, deve existir um Grupo Condutor Estadual e Municipal da Rede de Atenção às Urgências, cujas atribuições seriam: mobilizar os dirigentes políticos do SUS; apoiar a organização dos processos de trabalho voltados à implantação da rede; identificar e apoiar a solução de possíveis pontos críticos em cada fase; e monitorar e avaliar o processo de implantação da rede. Também é previsto que Comitês Gestores de Atenção às Urgências já existentes sejam mantidos e que sejam elaboradas propostas de estruturação e funcionamento de novos Comitês nos Âmbitos Estadual, Regional e Municipal nos locais onde ainda não existam. É sugerido que os Comitês Gestores Estaduais da Rede de Atenção às Urgências sejam integrados pelos mesmos componentes do Comitê em plano nacional (BRASIL, 2011a).

Infelizmente, no entanto, os comitês gestores têm sido apontados como inoperantes em alguns lugares. Destaca-se, ainda, a inexistência de reuniões regulares do Comitê Gestor Nacional (O’DWYER; MATTOS, 2012). A criação de uma nova instância gestora, com a recomendação da manutenção da original, não parece que contribuirá para a implantação da gestão por níveis.

Além do comitê nacional, as secretarias municipais e estaduais deverão constituir e coordenar seus respectivos comitês. São o espaço de discussão dos indicadores produzidos nesses níveis, cabendo ao estado a realização de relatórios a serem remetidos à CGUE.

\section{Financiamento}

A dinâmica do incentivo financeiro federal para o desenvolvimento da estratégia das UPAs integra as portarias nas suas três primeiras edições. Na portaria em 
vigor, $\mathrm{n}^{\circ} 2.648 / 2011$, as regras para o financiamento foram deslocadas para portarias específicas, sendo editadas até o momento quatro portarias, duas revogadas (2.820 e 2.821, de 2011) em duas em vigor (1.171 e 1.172, de 2012), específicas para recursos de investimento e custeio, respectivamente.

Inicialmente, os recursos para implantação das unidades resultavam de convênios entre os proponentes do projeto (estado ou município) e o Ministério da Saúde, mas apenas os recursos de custeio eram transferidos fundo a fundo. Posteriormente, todas as etapas das transferências financeiras passaram a ocorrer através de repasses fundo a fundo, por meio do Fundo Nacional de Saúde. Aspecto interessante que só consta da primeira portaria é a fixação do percentual a ser assumido pela União (50\%) no custeio das unidades, que desaparece das portarias subsequentes, embora permaneça o princípio de financiamento tripartite. A partir da primeira portaria de 2011, surge o conceito de qualificação, processo pelo qual uma UPA já habilitada, isto é, funcionando e recebendo repasses de custeio, é submetida à comprovação documental e visita técnica que permitem a ampliação dos recursos de custeio, quando a unidade é aprovada. Caso contrário, a UPA segue recebendo recursos de menor montante apenas pelo processo de habilitação, que consiste basicamente na comprovação de funcionamento da unidade.

Ao longo do tempo, algumas exigências para recebimento de recursos federais para construção de UPA permaneceram essencialmente as mesmas (quadro 3).

Quadro 3. Exigências para recebimento de recursos federais para Unidades de ProntoAtendimento na rede de atenção às urgências, Brasil, 2012

- Gestor local responsável deve prover a UPA $24 \mathrm{~h}$ com equipe horizontal de gestão do cuidado na unidade

- Quantitativo populacional a ser coberto pela UPA 24h, compatível com os respectivos portes de UPA $24 \mathrm{~h}$

- SAMU 192 habilitado na área de cobertura da UPA 24h, ou, na ausência deste, compromisso de implantação de SAMU dentro do prazo de implantação da UPA $24 \mathrm{~h}$

- Cobertura da Atenção Básica em Saúde de, no mínimo, 50\% da população do Município sede da UPA 24 h ou compromisso de implantação dessa cobertura

- Implantação da classificação de risco no acolhimento dos usuários na UPA $24 \mathrm{~h}$

- Grades de referência e contrarreferência pactuadas em nível locorregional com todos os componentes da Rede de Atenção às Urgências 
- Compromisso subscrito pelo responsável legal de pelo menos 1 (um) dos hospitais da grade de referência de garantia de retaguarda hospitalar para a UPA $24 \mathrm{~h}$

- Designação do coordenador da Coordenação da Rede de Urgência;

- Exclusividade de aplicação dos recursos financeiros repassados pela União para implantação da UPA $24 \mathrm{~h}$

- Plano de Ação Regional de Atenção Integral às Urgências ou, na sua ausência, compromisso de que a nova UPA 24 h estará inserida no citado Plano, quando da sua elaboração.

Fonte: Brasil (2012a, 2012b).

Em um cotejo entre as portarias, revogadas e em vigor, que versam sobre recursos financeiros, notamos aspectos relevantes. Primeiramente, as portarias em vigor definem, de forma inédita, o gestor a que se referem, admitindo tanto o chefe do Poder Executivo municipal ou estadual quanto os secretários de Saúde municipal ou estadual. Entendemos que essa definição é coerente com a diversidade de gestão das UPA, ora municipais, ora estaduais. Também há exigência de melhor comprovação do compromisso do gestor na garantia da retaguarda hospitalar. O compromisso formal de retaguarda deve ser confirmado pelo responsável legal de um dos hospitais integrantes da grade de referência, a fim de garantir a retaguarda hospitalar da UPA. A obrigatoriedade de realizar cadastramento no Sistema do Cadastro Nacional de Estabelecimentos de Saúde (SCNES) e alimentar os sistemas de informação do SUS persiste como exigência para repasse de recursos para implantação e custeio.

$\mathrm{Na}$ legislação mais recente, está previsto acréscimo de 30\% no custeio de UPA instalada na região Amazônia Legal, que não aparecia em nenhuma das portarias anteriores. Também é interessante notar que propostas para construção da UPA, apesar de continuarem requerendo aprovação do Conselho de Saúde do Município sede da UPA e pactuação na Comissão Intergestores Bipartite (CIB), não mais exigem pactuação na Comissão Intergestores Regional (CIR). A aprovação do projeto pela Vigilância Sanitária é exigida mas não está mais vinculada ao repasse de recursos. Também a habilitação para receber recursos de custeio deixou de exigir a expedição de alvará de funcionamento pelo órgão de vigilância sanitária local. 
No conjunto, essas portarias traduzem uma visão de que as UPAs devem ser instaladas de forma estratégica para a configuração das redes de atenção às urgências. A necessária coexistência com um SAMU e também a obrigatoriedade de expandir a cobertura de atenção primária são condicionalidades que procuram fortalecer a visão de rede e impelir os gestores a desenvolverem e investirem em outros componentes da rede de urgências. Segundo os autores dessas portarias, essa proposição marca a diferenciação pretendida entre a UPA e os antigos PS, produtores de "consultas de emergência" (BRASIL, 2008).

Nessa linha, destaca-se que a adesão ao Pacto pela Saúde, presente nas portarias anteriores, deixou de compor a lista de exigências, o que parece negativo para a atuação em rede. Por outro lado, porém, o compromisso com o desenvolvimento de atividades de educação permanente e a alimentação dos bancos de dados, aspectos fundamentais para a qualificação do cuidado e aprimoramento da rede, persistem como pontos positivos (BRASIL, 2008, 2009a, 2011d, 2011e, 2012a, 2012b).

Não há, contudo, garantias de que a formação da rede será o fio condutor da implantação dessas unidades. Exemplo disso é a experiência das unidades de assistência médica ambulatorial (AMA) paulistanas, consideradas um retrocesso na organização de um sistema de saúde que se pretende orientado para a Atenção Primária e um desrespeito aos princípios do SUS, além de não representarem resposta à lacuna do pronto-atender na ESF. Argumenta-se que as UPAs estejam se constituindo na versão federal das AMAs de São Paulo (PUCCINI, 2008). Semelhantemente, no município do Rio de Janeiro, a rápida expansão das UPAs se apoiou, segundo o discurso oficial, no grande déficit da rede de atenção básica municipal (O’DWYER, 2010).

Assim, a expansão das UPAs, sem uma franca organização em rede, projeta a suspeita de que essas novas unidades possam estar reproduzindo os criticados pronto-socorros tradicionais. Principalmente, porque o maior desafio para a política de urgência pré-hospitalar vem sendo sua integração com sua principal porta de saída - o hospital- e com a atenção básica, a porta de entrada reguladora do sistema (GAWRYSZEWSKI et al., 2012; KONDER, 2013).Vale destacar o caso do Rio de Janeiro, onde as UPAs foram implantadas em 2007, quando 
ainda não havia regulação federal para essas unidades. Nesse município, as UPAs se inseriram na rede de atenção à saúde reforçando e reproduzindo a dinâmica de fragmentação já estabelecida, resultando em integração limitada entre os pontos de atenção à saúde, fortemente dependente das relações interpessoais (GAWRYSZEWSKI et al., 2012; KONDER, 2013).

Alguns problemas relacionados à formulação e implantação das UPAs merecem destaque. Um deles é a limitação da atenção primária como componente da rede de urgências. Esse aspecto requer um enfrentamento complexo. Dividida entre o atendimento de demandas programadas e a demanda espontânea, a atenção primária, justificadamente, não consegue se responsabilizar pelo atendimento às urgências da sua população adscrita. Embora a PNAU identifique a necessidade de a atenção primária contar com as salas de observação para garantir o atendimento às urgências no seu horário de atendimento, a expansão da atenção primária no Brasil não ocorreu com um padrão de investimento arquitetônico coerente com essa necessidade. Por outro lado, a dificuldade de acesso ao hospital, tanto pela superlotação das emergências hospitalares, quanto pela escassez de leitos clínicos de enfermaria e leitos de terapia intensiva, também limita o impacto da atuação das UPAs. Essas unidades têm simultaneamente a possibilidade de prover atendimento inicial complexo a pacientes graves e atendimento de média e baixa complexidade mais perto da casa das pessoas. Todavia, as dificuldades de conformação de uma rede têm restringido o benefício que essas unidades poderiam representar.

Outro problema relacionado à expansão de serviços novos, incluindo aí a expansão da atenção primária, é a constante dificuldade de lotação de profissionais médicos. Com as UPAs não tem sido muito diferente. No município do Rio de Janeiro, a disponibilidade de profissionais médicos, sobretudo pediatras, é crítica na maioria das unidades (KONDER, 2013). Percebe-se que, na verdade, esses diversos tipos de serviços estão competindo pelos mesmos profissionais, sem que se alterem as dificuldades que todos encontram na fixação dos médicos. Por fim, outro fator coercitivo tem sido a não integração do sistema de informação nos serviços de urgência e a falta de atuação dos comitês gestores, além de estratégias de terceirização da gestão das unidades, que têm ocorrido em alguns municípios (KONDER, 2013). 


\section{Conclusão}

No atual cenário de atendimento às urgências, nos deparamos com um projeto de atenção às urgências que se pretende integrador, mas foi proposto de forma fragmentada, iniciando-se pelo SAMU e posteriormente pelas UPAs. Ambos os componentes vêm sofrendo de dificuldades de integração com a rede de serviços com significativo prejuízo para a integralidade do cuidado (O'DWYER; MATTOS, 2013; KONDER, 2013).

A implantação da política de urgência foi amparada pela lógica de indução financeira pelo Estado e de forte expansão da rede. A principal estratégia da política foi criar novas unidades assistenciais, embora recentemente haja a possibilidade de habilitar unidades já existentes. Os serviços hospitalares de emergência, os grandes "vilōes" do sistema, apesar dos programas QualiSUS-urgência e SOS Emergência, não sofreram modificação consistentes que impactassem o atendimento. A atual RAU tenta resgatar o investimento em hospitais através das linhas de cuidado.

Em novembro de 2012, havia em funcionamento no Brasil 228 UPAs, além de haver mais 646 em execução, em um total de 874, conforme dados disponíveis na página oficial do Ministério da Saúde na internet. Apenas sete estados da federação agregavam perto de $90 \%$ das UPAs em funcionamento, com destaque para o Rio de Janeiro, com maior número de unidades no país, tendo sido primeiro a implantar UPAs, antes mesmo da regulação federal.

Atualmente, são 291 UPAs em funcionamento, das quais $68,3 \%$ foram construídas com recursos do Governo Federal (tabela 1). O peso do financiamento federal é maior nas regiōes Nordeste, Norte e Centro Oeste. O número de UPAs atualmente em execução indica que este irá triplicar nos próximos anos, mantendo, porém, a atual distribuição dessas unidades entre as regiōes do país. Nota-se, dessa forma, que as UPAs estão em franca expansão, apesar das dificuldades identificadas até o presente.

Observando-se a evolução da formulação e implantação das UPAs, com destaque para os números acima, percebe-se que a prioridade, por parte do Governo Federal, para essa política, foi grande, bem como foi significativa a adesão das unidades da federação. Assim, pode-se inferir que foi ampla a legitimação, enquanto modalidade da estruturação, alcançada por essa política. Vale ressaltar que regulação normativa aliada ao aporte financeiro vem sendo a 
estratégia adotada pelo Ministério da Saúde na indução de mudanças e promoção de políticas na área da saúde.

Tabela 1. Número de UPAs em funcionamento total e construídas com recursos do MS, número de UPA em execução e proporção de UPAs construídas com recursos do MS, 2013

\begin{tabular}{lllll}
\hline Regióes & $\begin{array}{l}\text { UPAs em } \\
\text { funcionamento }\end{array}$ & $\begin{array}{l}\text { UPAs } \\
\text { financiamento } \\
\text { MS }\end{array}$ & $\begin{array}{l}\text { \% UPAs } \\
\text { investimento } \\
\text { MS }\end{array}$ & $\begin{array}{l}\text { UPAs em } \\
\text { execução }\end{array}$ \\
\hline Sudeste & 156 & 96 & $61,5 \%$ & 352 \\
\hline Nordeste & 69 & 54 & $78,3 \%$ & 267 \\
\hline Sul & 35 & 24 & $68,6 \%$ & 157 \\
\hline Centro Oeste & 18 & 15 & $83,3 \%$ & 98 \\
\hline Norte & 13 & 10 & $76,9 \%$ & 92 \\
\hline Total & 291 & 199 & - & 966 \\
\hline
\end{tabular}

Fonte: DAE/SAS/Ministério da Saúde, novembro 2013 (www.saude.gov.br/sage).

Nesse período inicial da política das UPAs no Brasil, identificamos um processo político de acomodação de interesses e de geração de expectativas. Formuladores de políticas, a partir de um problema e de uma intenção, propõem uma norma que reflete seus interesses, mas que é produzida em um cenário de disputa. A formulação de uma política tem que ser entendida essencialmente como um processo político, em vez de um processo analítico de solução de problema. É um processo de negociação, barganha e acomodação de muitos diferentes interesses que refletem a ideologia do governo em poder (WALT, 1994). Assim, a convergência de interesses em torno da UPA permitiu rápida expansão e enorme aporte de recursos para essa política, apesar de essa estratégia encontrar grandes dificuldades na sua implementação, pouco agregando para o enfrentamento dos problemas da atenção às urgências.

A regulamentação do atendimento às urgências no Brasil é recente, e a UPA é o último componente implementado. Este estudo pretendeu analisar as condições de implementação propostas na regulamentação federal. Entretanto, estudos empíricos sobre essa implementação são necessários para a continuidade dessa análise. ${ }^{2}$ 
BITTENCOURT, R. J.; HORTALE, V. A. Intervenções para solucionar a superlotação nos serviços de emergência hospitalar: uma revisão sistemática. Cad. saúde pública. Rio de Janeiro, v. 25, n.7, p.1439-1454, 2009.

BRASIL. Ministério da Saúde. Portaria no 1.863, de 29 de setembro de 2003. Institui a Política Nacional de Atenção às Urgências, a ser implantada em todas as unidades federadas, respeitadas as competências das três esferas de gestão. Diário Oficial da União, Brasília, DF, 06 out. 2003a. p. 56.

. Ministério da Saúde. Portaria no 1.864, de 29 de setembro de 2003. Institui o componente pré-hospitalar móvel da Política Nacional de Atenção às Urgências, por intermédio da implantação de Serviços de Atendimento Móvel de Urgência em municípios e regiōes de todo o território brasileiro: SAMU-192. Diário Oficial da União, Brasília, DF, 06 out. 2003 b. p. 57.

Ministério da Saúde. Portaria no 2.072, de 30 de outubro de 2003. Institui o Comitê Gestor Nacional de Atenção às Urgências. Diário Oficial da União, Brasília, DF, 31 out. 2003c. p. 44.

Ministério da Saúde. Portaria no 2.922, de 2 de dezembro de 2008. Estabelece diretrizes para o fortalecimento e implementação do componente de "Organização de redes loco-regionais de atenção integral às urgências" da Política Nacional de Atenção às Urgências. Diário Oficial da União, Brasília, DF, 03 dez. 2008. p. 66.

- Ministério da Saúde. Portaria no 1.020, de 13 de maio de 2009. Estabelece diretrizes para a implantação do componente pré-hospitalar fixo para a organização de redes locorregionais de atenção integral às urgências em conformidade com a Política Nacional de Atenção às Urgências. Diário Oficial da Uniāo, Brasília, DF, 15 mai. 2009. p. 59.

. Ministério da Saúde. Portaria no 1.600, de 7 de julho de 2011. Reformula a Política Nacional de Atenção às Urgências e institui a Rede de Atenção às Urgências no Sistema Único de Saúde (SUS). Diário Oficial da União, Brasília, DF, 08 jul. 2011a. p. 70.

. Ministério da Saúde. Portaria no 1.601, de 7 de julho de 2011. Estabelece diretrizes para a implantação do componente Unidades de Pronto-atendimento (UPA 24h) e o conjunto de serviços de urgência 24 horas da Rede de Atenção às Urgências, em conformidade com a Política Nacional de Atenção às Urgências. Diário Oficial da União, Brasília, DF, 08 jul. 2011b. p. 70.

Ministério da Saúde. Portaria no 2.648, de 7 de novembro de 2011. Redefine as diretrizes para implantação do Componente Unidade de Pronto-atendimento (UPA 24h) e do conjunto de serviços de urgência 24 (vinte e quatro) horas da Rede de Atenção às Urgências, em conformidade com a Política Nacional de Atenção às Urgências. Diário Oficial da União, Brasília, DF, 08 nov. 2011c. p. 48. 
Ministério da Saúde. Portaria no 2.820, de 28 de novembro de 2011. Dispõe sobre o incentivo financeiro de investimento para o Componente Unidade de ProntoAtendimento (UPA 24h) e o conjunto de serviços de urgência 24 horas da Rede de Atenção às Urgências, em conformidade com a Política Nacional de Atenção às Urgências. Diário Oficial da Uniāo, Brasília, DF, 30 nov. 2011d. p. 112.

. Ministério da Saúde. Portaria no 2.821, de 28 de novembro de 2011. Dispõe sobre o incentivo financeiro de custeio para o Componente Unidade de Pronto-Atendimento (UPA 24h) e o conjunto de serviços de urgência 24 horas da Rede de Atenção às Urgências, em conformidade com a Política Nacional de Atenção às Urgências. Diário Oficial da União, DF, 30 nov. 2011e. p. 113.

. Ministério da Saúde. Portaria no 1.171, de 5 de junho de 2012. Dispõe sobre o incentivo financeiro de investimento para construção e ampliação no âmbito do Componente Unidade de Pronto-Atendimento (UPA 24h) e do conjunto de serviços de urgência 24 horas da Rede de Atenção às Urgências, em conformidade com a Política Nacional de Atenção às Urgências. Diário Oficial da União, Brasília, DF, 06 jun. 2012a. p. 128.

. Ministério da Saúde. Portaria no 1.172, de 5 de junho de 2012. Dispóe sobre o incentivo financeiro de custeio para o Componente Unidade de Pronto-Atendimento (UPA 24h) e o conjunto de serviços de urgência 24 horas da Rede de Atenção às Urgências, em conformidade com a Política Nacional de Atenção às Urgências. Diário Oficial da União, Brasília, DF, 06 jun. 2012b. p. 129.

CICONET, R. M.; MARQUES, G. Q.;LIMA, M. A. D. S.; Educação em serviço para profissionais do Serviço de Atendimento Móvel de Urgência (SAMU): relato da experiência de Porto Alegre/RS. Interface comun. saúde educ. Botucatu, v. 12, n. 26, p. 659-666, 2008. EVANGELISTA, P. A.; BARRETO, S. M.;GUERRA, H. L. Central de regulação de leitos do SUS em Belo Horizonte, Minas Gerais: avaliação de seu papel pelo estudo das internações por doenças isquêmicas do coração. Cad. saúde pública, Rio de Janeiro, v. 24, n. 4, p. 767-776, 2008.

GAWRYSZEWSKI, A. R. B.; OLIVEIRA, D. C.; GOMES, A. M. T. Acesso ao SUS: representações e práticas de profissionais desenvolvidas nas Centrais de Regulação. Physis: Revista de Saúde Coletiva, Rio de Janeiro,v. 22, n. 1, p. 119-140, 2012.

GIDDENS, A. A constituição da Sociedade. São Paulo: Martins Fontes, 1984.

GIGLIO-JAQUEMOT, A. Urgências e emergências em saúde: perspectivas de profissionais e usuários. Rio de Janeiro: Fiocruz, 2005.

KONDER, M. T. Atenção às urgências: a integração das Unidades de Pronto-atendimento 24 horas (UPA 24h) com a rede assistencial no município do Rio de Janeiro. 2013. 108 f. Dissertação (Mestrado Acadêmico em Saúde Pública) - Escola Nacional de Saúde Pública, Fundação Oswaldo Cruz,Rio de Janeiro, 2013. 
LIMA, J. C.; RIVERA, F. J. U. Redes de conversação e coordenação de ações de saúde: estudo em um serviço móvel regional de atenção às urgências. Cad. saúde pública, Rio de Janeiro, v. 26, n.2, p.323-336, 2010.

MACHADO, C. V.;SALVADOR, F. G. F.; O’DWYER, G. Serviço de Atendimento Móvel de Urgência: análise da política brasileira. Rev. saúde pública. São Paulo, v. 45, n. 3, p. 519528, 2011.

MINAYO, M. C. S.; DESLANDES, S. F. Análise da implantação do sistema de atendimento pré-hospitalar móvel em cinco capitais brasileiras. Cad. saúde pública. Rio de Janeiro, v. 24, n. 8, p. 1877-1886, 2008.

O’DWYER, G. A gestão da atenção às urgências e o protagonismo federal. Ciênc. Saúde coletiva, Rio de Janeiro, v. 15, n. 5, p. 2395-2404, 2010.

O'DWYER, G. et al. The current scenario of emergency care policies in Brazil. BMC health serv. res. (Online), London, v. 13, n. 70, 2013b.Disponível em: <http://www.biomedcentral. com/1472-6963/13/70>. Acesso em: 20 fev. 2013.

O’DWYER, G.; MATTOS, R. A. O cuidado integral e a atenção às urgências: o Serviço de Atendimento Móvel de Urgências no Estado do Rio de Janeiro. Saúde Soc. São Paulo, v. 22, n.1, p. 199-210, 2013a.

. O SAMU, a regulação no estado do Rio de Janeiro e a integralidade segundo gestores dos três níveis de governo. Physis: Revista de Saúde Coletiva, Rio de Janeiro, v. 22, n. 1, p. 141-160, 2012.

O’DWYER, G.; OLIVEIRA, S. P.; SETA, M. H. Avaliação dos serviços hospitalares de emergência do programa QualiSUS. Ciênc. saúde coletiva, Rio de Janeiro, v. 14, n. 5, p. 1881-1890, 2009.

PUCCINI, P. T. As unidades de assistência médica ambulatorial (AMA) do município de São Paulo, Brasil: condições de funcionamento e repercussões sobre a atenção básica no Sistema Único de Saúde, 2006. Cad. saúde pública, Rio de Janeiro, v. 24, n. 12, p. 2755 2766, 2008.

SAGE. Sala de Apoio à Gestão Estratégica. Desenvolvido pelo Ministério da Saúde. Disponível em: <www.saude.gov.br/sage> Acesso em: 05 jan. 2014.

SANTOS, J. S.et al. Avaliação do modelo de organização da unidade de emergência do HCFMRP-USP, adotando, como referência, as políticas nacionais de atenção às urgências e de humanização. Medicina, Ribeirão Preto, v. 36, n. 2/4, p. 498-515, 2003.

TANNENBAUM, R. D.; ARNOLD, J. L. Emergency Medicine in Southern Brazil. Ann. Emerg. Med., Dallas, v. 37, n. 2, supl., p. 223-228, 2001.

WALT, G. Health Policy. An Introduction to Process and Power. Johannesburg: Witwatersrand University Press; 1994. 
${ }^{1}$ Municípios com menos de 50 mil habitantes não são candidatos à implantação de Unidades de Pronto-Atendimento. Nesses casos, a política prevê a instalação de salas de estabilização, que são estruturas menores com a finalidade de prover atendimento a casos graves temporariamente.

${ }^{2}$ M. T. Konder participou da concepção, planejamento, execução e interpretação do estudo. G. O'Dwyer participou do planejamento, execução e interpretação do estudo. 
The emergency care units in the National Policy for Emergency

The National Policy for Emergency was the result of great dissatisfaction with care in emergency departments. The UPA's (emergency care units) were the main component of fixed pre-hospital care policy. This study aimed to analyze the ministerial decrees that regulated the creation of UPA's, trying to understand their deployment pattern. The ordinances were analyzed that regulated UPA's between 2008 and 2013 in the light of Structuring Theory, by Giddens. Taken together, these ordinances express the claim that the UPA's were installed strategically to the configuration of the emergency care networks, offering differentiation from emergency rooms producers of "emergency consultations". However, the pattern of deployment of UPA's was accelerated expansion without effective network organization, arising suspicion of reproduction of the traditional model of emergency rooms. The federal level was highlighted by the intense production rules, taking strong inducing role. The significant participation of units of the federation explains the wide legitimacy, as a method of structuring achieved by this policy. The convergence of interests around the UPA's allowed rapid expansion and huge allocation of resources to this policy, even though this little add strategy to face the problems of attention to emergency rooms.

Key words: prehospital emergency care; emergency medical services; Unified Health System. 